\title{
Gastrin, gastric acid secretion, and gastric microflora in patients with rheumatoid arthritis
}

\author{
K HENRIKSSON, ${ }^{1}$ K UVNÄS-MOBERG,$^{3}$ C-E NORD ${ }^{4}$ C JOHANSSON ${ }^{2}$ AND \\ R GULLBERG ${ }^{1}$
}

From the ${ }^{1}$ Department of Rheumatology and the ${ }^{2}$ Department of Medicine, Karolinska Hospital; the

${ }^{3}$ Department of Pharmacology, Karolinska Institute, and the ${ }^{4}$ National Bacteriological Laboratory, Stockholm Sweden

SUMMARY The relation between the basal and stimulated gastric acid secretion, plasma gastrin, and the gastric microflora was examined in 45 patients with rheumatoid arthritis. Sixteen patients $(36 \%)$ had basal achlorhydria, and of these, $10(22 \%)$ had achlorhydria or hypochlorhydria after stimulation with pentagastrin. The peak acid output and acidity showed inverse correlation with the disease duration but were not associated with age or with the degree of physical disability. Hypergastrinaemia was found in nine patients $(20 \%)$, of whom $6(13 \%)$ had significant titres of parietal cell antibody. The acidity of the peak acid output showed negative correlation with plasma gastrin. It was confirmed that the gastric secretory state is a determinant of plasma gastrin levels and in addition influences the growth of micro-organisms in the gastric lumen. The type of microflora in the non-acid stomach was similar to that found in the saliva. A subgroup of eight females was identified who showed low gastric acid secretion rates, positive bacterial cultures, and atlantoaxial subluxation. Gastrin- and insulin-like immunoreactivities were found in joint fluid. The concentrations reflected their plasma levels, suggesting that the peptides are not released at the inflammatory site, but rather that they reach synovial fluid from circulating blood.

Key words: atlantoaxial joint, gastritis—atrophic, insulin, peptides, saliva, synovial fluid.

Previous studies have shown that patients below 40 years of age with rheumatoid arthritis (RA) have a reduced gastric secretory capacity. ${ }^{1-3}$ Raised plasma gastrin levels in RA were reported first by Rooney et al in $1973,{ }^{4}$ but gastric acid secretion was not examined. An inverse relation between gastric acid secretion and plasma gastrin was reported in such patients by Rowden et al,,$^{5}$ but the frequency of achlorhydria was similar to that of normal controls. In a subsequent study De Witte et al confirmed that increased plasma gastrin was found in patients with achlorhydria or low acid secretion and there was also a higher frequency of reduced gastric acid secretion in the RA patients. ${ }^{6}$ On the other hand, hypergastrinaemia in the presence of normal parietal cell function has been reported in patients with $\mathrm{RA},{ }^{7} 8$ and this also has been reported in experimental arthritis in the rat. ${ }^{910}$ Since gastrin may be released from somatic nerves in animals ${ }^{11}$ the

Accepted for publication 10 October 1985

Correspondence to Dr K Henriksson, Department of Rheuma.tology, Karolinska Hospital, S-104 01 Stockholm, Sweden. possibility should be considered that hypergastrinaemia in RA may be due partly to extragastric release.

The gastric microbial pattern is known to change in achlorhydria, ${ }^{12}{ }^{13}$ and it has been suggested by Olhagen, ${ }^{14}$ Gullberg, ${ }^{15}$ and Bennett ${ }^{16}$ that bacterial antigens or other biologically active substances from the gastrointestinal microflora may be of importance as a causative or perpetuating factor in RA.

The present study was designed to analyse further the inter-relation between plasma gastrin, basal and stimulated gastric acid secretion, and gastric microflora in patients with rheumatoid arthritis. Determinations of gastrin- and insulin-like immunoreactivity in joint fluid in parallel with blood plasma were also performed in order to assess possible release of these peptides at the inflammatory site.

\section{Patients and methods}

PATIENTS

Forty five patients ( 21 male and 24 female) with an 
average age of 57 years (range 24-79) were examined. All patients had 'classical' or 'definite' RA according to the criteria of the American Rheumatism Association. ${ }^{17}$ All patients had symmetrical, peripheral arthritis; in 39 patients the arthritis was erosive, and 44 patients were seropositive for rheumatoid factor. Sixteen had subcutaneous nodules. Thirty three patients had cervical spine symptoms, and of these, 11 had atlantoaxial subluxation on $x$ ray examination. Four of these patients, all female, had such severe instability that surgery was indicated. The mean duration of the disease was 7.5 years (range three months to 24 years) dated from the onset of symptoms. The physical disability of the patients was evaluated as functional capacity and graded I to IV. ${ }^{18}$ Twenty four patients were in grade II and 21 in grade III. One patient had undergone antrectomy for recurrent gastric ulcer. All patients had normal renal function and none of the patients had pernicious anaemia (PA).

Only five patients were without medication at the time of the study. The remaining 40 patients were receiving non-steroidal anti-inflammatory drugs (NSAIDs). In addition, 14 patients were on maintenance treatment with prednisolone at a daily dose of $5-10 \mathrm{mg}$ and one patient received two to three injections of adrenocorticotrophic hormone every week. In combination with predisolone or NSAIDs, or both, 12 patients had chloroquine and five patients penicillamine. Proresid, an antimitotic cytostatic agent, was given to a further three other patients. Thirteen patients had had only NSAIDs, i.e., first line antirheumatic drugs, during their disease, while the other 32 patients had been further treated with the aforementioned second line or third line drugs, or both, for at least two months.

All patients were evaluated clinically and divided arbitrarily into three groups with low, moderate, and high disease activity respectively. Laboratory parameters for the three groups are reported in Table 1.

\section{PROCE D URE}

The patients fasted overnight with the last medication given 12-16 hours before the study.

In the morning blood for hormone analysis was prepared in prechilled, heparinised tubes and centrifuged at $4^{\circ} \mathrm{C}$. The plasma was separated and kept frozen at $-70^{\circ} \mathrm{C}$ until assayed. Saliva samples were obtained from 14 patients and cultured both aerobically and anaerobically.

Before swallowing a tube for the gastric secretion test patients rinsed the mouth with an antiseptic solution of ascorbic acid, sodium bicarbonate, and copper sulphate (Ascoxal). With the patient lying on
Table 1 Laboratory parameters in patient groups with low, moderate, orhigh disease activity as evaluated clinically*

\begin{tabular}{|c|c|c|c|}
\hline & \multicolumn{3}{|c|}{ Disease activity } \\
\hline & $\begin{array}{l}\text { Low } \\
(n=6)\end{array}$ & $\begin{array}{l}\text { Moderate } \\
(n=23)\end{array}$ & $\begin{array}{l}\text { High } \\
(n=I 6)\end{array}$ \\
\hline$\overline{\mathrm{ESR}^{\dagger}}(\mathrm{mm} / \mathrm{lst} \mathrm{h})$ & $\begin{array}{l}17 \\
(4-49)\end{array}$ & $\begin{array}{l}39 \\
(10-95)\end{array}$ & $\begin{array}{l}73 \\
(29-130)\end{array}$ \\
\hline $\mathrm{CRP}^{\dagger}(\mathrm{mg} / \mathrm{l})$ & $\begin{array}{l}<5 \\
(<5)\end{array}$ & $\begin{array}{l}18 \\
(<5-34)\end{array}$ & $\begin{array}{l}46 \\
(12-63)\end{array}$ \\
\hline Haptoglobin (g/l) & $\begin{array}{l}2 \cdot 1 \\
(1 \cdot 3-2 \cdot 6)\end{array}$ & $\begin{array}{l}3 \cdot 3 \\
(1 \cdot 8-4 \cdot 5)\end{array}$ & $\begin{array}{l}4 \cdot 5 \\
(2 \cdot 9-6 \cdot 4)\end{array}$ \\
\hline
\end{tabular}

*Values are mean and ranges.

${ }^{\dagger} \mathrm{ESR}=$ erythrocyte sedimentation rate; $\mathrm{CRP}=\mathrm{C}$ reactive protein.

the left side the tube (Fg 14, Portex, England) was 을 positioned in such a way as to permit an optimal recovery. Saliva was removed by suction. After three $15 \mathrm{~min}$ collections of the basal secretion, pentagastrin $6 \mu \mathrm{g} / \mathrm{kg}$ (Peptavlon) was given as a subcutaneous injection. A further four collections of gastric secretions were made at 15 min intervals after stimulation. Two to four millilitre samples of the gastric contents were aspirated through a sterile syringe for culture $15 \mathrm{~min}$ before and $45 \mathrm{~min}$ after the pentagastrin injection.

In an additional study samples of blood and joint fluid from a further 12 patients with classical, seropositive rheumatoid arthritis were withdrawn at the same time for assay of gastrin and insulin concentrations. Nine patients had fasted overnight and three patients had had a light morning meal one to two hours before sampling.

RADIOIMMUNOLOGICAL DETERMINATIONS Gastrin levels were determined according to the method described by Nilsson ${ }^{19}$ using antiserum 2604, a gift kindly given by Professor J Rehfeld, Copenhagen. This antiserum recognises gastrin 17 and 34 and unsulphated and sulphated forms of gastrin with the same potency. Insulin determi- of nations were performed with the radioimmunoassay $N$ described by Nilsson and Uvnäs-Wallensten, ${ }^{20}$ with an antiserum kindly given by Professor S Efendić, Stockholm.

ANALYSES OF GASTRIC JUICE

The volume and the $\mathrm{pH}$ of each $15 \mathrm{~min}$ gastric collection were determined. The acidity of samples $\bar{O}$ was determined by titration with $0.1 \mathrm{M} \mathrm{NaOH}$ to pH 7 (Radiometer, Copenhagen). The basal gastric $\mathbb{D}$ acid output (BAO) is defined as the acid secretion during $30 \mathrm{~min}$ before stimulation; the peak acid output (PAO) is defined as the sum of the two 
highest consecutive measurements after pentagastrin administration.

\section{MICROBIOLOGICAL INVESTIGATIONS}

The saliva specimens from 14 patients and samples of basal and stimulated gastric secretion from 39 patients were transported anaerobically to the laboratory and prepared for microbial cultures within two hours after sampling. Fifty eight gastric samples, 28 each from basal and stimulated periods, were examined both with and without manipulation of the $\mathrm{pH}$. If the $\mathrm{pH}$ was below 4 part of the sample was adjusted to $\mathrm{pH} 7 \cdot 0$ with $\mathrm{NaOH}$, if above 4 to $\mathrm{pH}$ 1.8 with $\mathrm{HCl}$. The $\mathrm{pH}$ adjustment was made immediately after withdrawal of samples, which were thereafter identically treated.

The samples were suspended in prereduced peptone-yeast extract medium, ${ }^{21}$ diluted, inoculated in media, and handled as described by Heimdahl and Nord. ${ }^{22}$ The aerobic agar plates were incubated for $24 \mathrm{~h}$ at $37^{\circ} \mathrm{C}$ and the anaerobic plates for $48 \mathrm{~h}$ at $37^{\circ} \mathrm{C}$ in anaerobic jars (Gas Pak, BBL, Cockeysville, Maryland, USA). They were then examined, and colonies were counted under a stereomicroscope.

Aerobic bacteria were identified biochemically as described elsewhere, ${ }^{22}$ and anaerobic bacteria were identified by biochemical tests and gas-liquid chromatography. ${ }^{21}$

\section{STATISTICAL METHODS}

Values are given as mean \pm SD or range. Wilcoxon's non-parametric rank test and the $\chi^{2}$ test were used to test significance. Correlation coefficients were calculated according to Spearman.

\section{Results}

GASTRIC ACID

The average basal gastric output (BAO) was
$0.43 \mathrm{mmol} / 30 \mathrm{~min}$ (range $0-2.4$ ), and the peak acid output (PAO) after pentagastrin administration was $7.4 \mathrm{mmol} / 30 \mathrm{~min}$ (range $0-23.8$ ). The antrectomised patient was achlorhydric. Sixteen of the other 44 patients $(36 \%)$ were achlorhydric in the basal state. Of these, four had no acid response to stimulation and the PAO was less than $1.30 \mathrm{mmol} / 30 \mathrm{~min}$ in an additional six patients. Female patients of all age groups had low average and peak gastric acid secretion rates. The secretion rate declined with age in the male patients (Table 2). The PAO (Fig. 1) was inversely proportional to disease duration $(r=-0 \cdot 39, n=44, p<0 \cdot 01)$ but showed no correlation with either the inflammatory activity or the degree of physical disability.

The eight female patients with atlantoaxial subluxation had all received second line or third line drugs, or both, and had significantly lower basal $(p<0.02)$ and stimulated $(p<0.01)$ gastric acid secretion rates compared with those of the female patients without this cervical spine complication (Table 3). The four patients with severe atlantoaxial instability had all basal achlorhydria and PAO below $1.3 \mathrm{mmol} / 30 \mathrm{~min}$. In comparison, male patients with atlantoaxial subluxation had fewer abnormalities of gastric functions.

\section{PLASMA GASTRIN}

The average fasting plasma gastrin level was 112 $\mathrm{pg} / \mathrm{ml}$ (range 2 to $>600$ ) and exceeded 100 $\mathrm{pg} / \mathrm{ml}$ in nine patients. There was no sex difference, and correlations with age or disease duration were absent. There was a statistically significant inverse relationship between log plasma gastrin and PAO $(r=-0.51, n=37, p<0.01)$ and even more impressively with the acidity of the peak secretion (Fig. 2). Female patients who had been treated with second line or third line drugs, or both, had significantly higher plasma gastrin levels than female patients treated only with NSAIDs $(p<0 \cdot 05)$.

Table 2 Basal (BAO) and peak (PAO) stimulated gastric acid secretion in 44 RA patients according to age and sex (the antrectomised patient excluded)

\begin{tabular}{|c|c|c|c|c|c|}
\hline & & \multicolumn{3}{|c|}{ Patients of age (years): } & \multirow[t]{2}{*}{ All patients } \\
\hline & & $<50$ & $50-60$ & $>60$ & \\
\hline \multirow{3}{*}{$\mathrm{BAO}(\mathrm{mmol} / 30 \mathrm{~min})$} & Female & $0 \cdot 26 \pm 0.29^{*}$ & $0.29 \pm 0.39$ & $0 \cdot 42 \pm 0 \cdot 70$ & $0 \cdot 31 \pm 0 \cdot 45$ \\
\hline & & $(6)^{*}$ & $(11)$ & (6) & $(23)$ \\
\hline & Male & $\begin{array}{l}1 \cdot 10 \pm 1 \cdot 20 \\
(4)\end{array}$ & $\begin{array}{l}0.45 \pm 0.57 \\
\text { (11) }\end{array}$ & $\begin{array}{l}0 \cdot 38 \pm 0 \cdot 63 \\
(6)\end{array}$ & $\begin{array}{l}0 \cdot 55 \pm 0 \cdot 74 \\
(21)\end{array}$ \\
\hline \multirow{4}{*}{ PAO (mmol/30 $\mathrm{min})$} & Femalc & $6 \cdot 2 \pm 5 \cdot 4$ & $6 \cdot 2 \pm 5 \cdot 5$ & $4 \cdot 6 \pm 6 \cdot 3$ & $5 \cdot 8 \pm 5 \cdot 5$ \\
\hline & & (6) & (11) & (6) & $(23)$ \\
\hline & Male & $9 \cdot 4 \pm 5 \cdot 1$ & $11 \cdot 5 \pm 7 \cdot 7$ & $5 \cdot 2 \pm 4 \cdot 5$ & $9 \cdot 3 \pm 6 \cdot 8$ \\
\hline & & (4) & (11) & (6) & $(21)$ \\
\hline
\end{tabular}

*Values are mean $\pm \mathrm{SD}$; No of patients given in parentheses. 


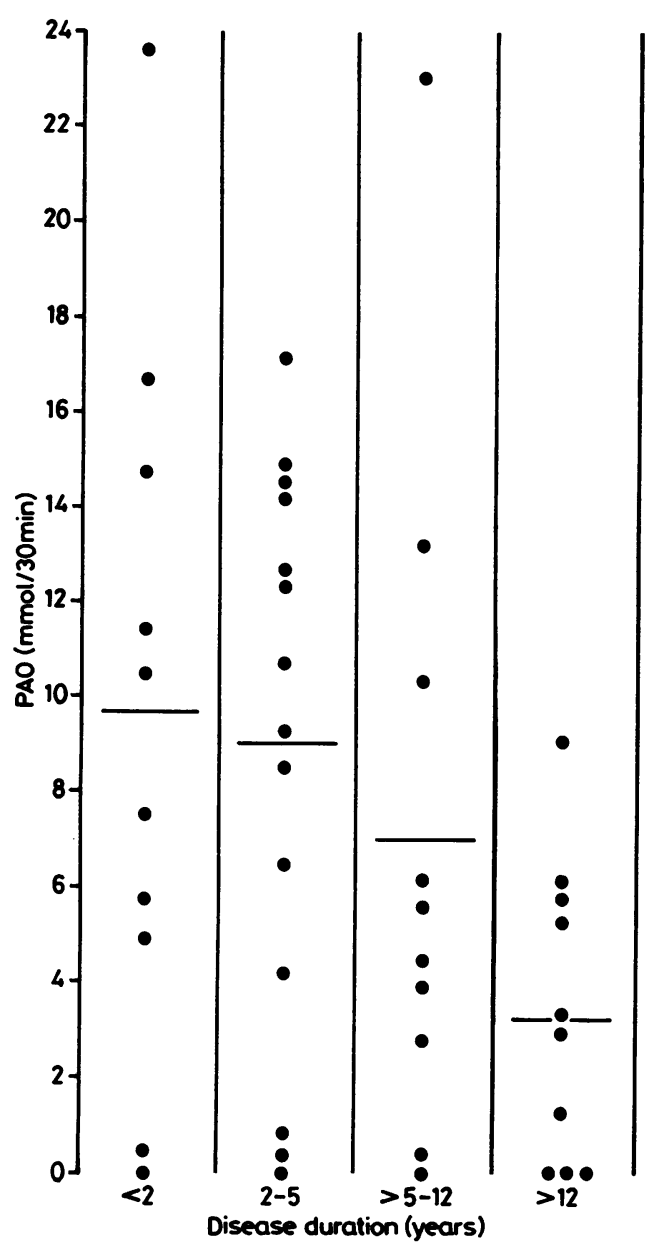

Fig. 1 Peak acid output after pentagastrin in 44 RA patients in relation to disease duration. Horizontal bars=mean values in the group.

PLASMA INSULIN

The fasting insulin level in 30 patients examined was $20 \pm 2 \cdot 4 \mu \mathrm{U} / \mathrm{ml}$ (range 5-56). Patients on second line or third line drugs had significantly $(p<0 \cdot 01)$ higher average plasma insulin levels $(27 \cdot 0 \pm 13 \cdot 2 \mu \mathrm{U} / \mathrm{ml})$ than patients on NSAIDs $(11 \cdot 0 \pm 5 \cdot 8 \mu \mathrm{U} / \mathrm{ml})$.

PARIETAL CELL ANTIBODY (PCA)

Nine patients had significant titres of PCA (1/25 or more). The average PAO in these patients was $2 \cdot 7$ $\mathrm{mmol} / 30 \mathrm{~min}$ (range $0-14 \cdot 8$ ), and the average plasma gastrin was $289 \mathrm{pg} / \mathrm{ml}$ (range 14-600). Of nine patients with plasma gastrin levels above $100 \mathrm{pg} / \mathrm{ml}$, six had PCA. The frequency of PCA (Table 3) was significantly higher in the female patients treated $\stackrel{?}{?}$ with second line or third line drugs, or both, than in $\overrightarrow{\vec{F}}$ the other patients $(p<0 \cdot 01)$.

GASTRIN AND INSULIN IN PLASMAAND JOIN T F LUID

Gastrin- and insulin-like immunoreactivities were found in the joint fluid of all patients examined (Table 4). The average ratio between fasting plasma and joint fluid levels of gastrin was 0.62 and of $\overrightarrow{\vec{\omega}}$ insulin $0 \cdot 71$.

SALIVARY AND GASTRIC MICROFLORA Of the 39 patients studied, 26 had positive microbial cultures in basal gastric juice. Eight patients had microbial growth both in basal and stimulated ov gastric contents. Candida species alone appeared in $\mathrm{O}$ five cultures from four patients.

The finding of positive microbial cultures was $\vec{\complement}$ clearly related to gastric acidity (Fig. 3). Growth of $\frac{\bar{\sigma}}{\vec{D}}$ micro-organisms in basal secretion was found in $12 \vec{\circ}$ out of 14 patients with basal achlorhydria. The additional 11 patients with positive microbial cultures had an average BAO of $0.23 \mathrm{mmol} / 30 \mathrm{~min}$, with an acidity within a range of $1-16 \mathrm{mmol} / \mathrm{l}$. In 13 patients with negative microbial cultures the basal secretion averaged $0.90 \mathrm{mmol} / 30 \mathrm{~min}$ and the acidity ranged from 1 to $80 \mathrm{mmol} / \mathrm{l}$.

All five patients with a PAO below $0.06 \mathrm{mmol} / 30 \overrightarrow{\overrightarrow{0}}$ min (acidity $0-6 \mathrm{mmol} / \mathrm{l}$ ) had positive microbial $\exists$ cultures in the stimulated secretion. Only one of the 34 remaining patients with stimulated acidity exceeding $27 \mathrm{mmol} / \mathrm{l}$ had microbial growth (Bacteroides eggerthi).

The number of patients with positive microbial culture in the stimulated period was significantly higher in female patients with atlantoaxial subluxation than in other female patients (Table 3 ).

CHARACTERISTICS OF GASTRIC MICROFLORA $\frac{7}{2}$ The patterns of salivary and gastric microbial growth were similar (Fig. 4), but only in a single patient (No $\sigma$ 12) were the gastric flora identical to the salivary $N$ microflora (Fig. 5). Only one patient, who had $\mathrm{N}$ undergone antrectomy, had a faecal type of gastric microflora.

EFFECTS OF PH ADJUSTMENT ON THE MICROFLORA RECOVERED

To evaluate the effect of sample $\mathrm{pH}$ on microbial

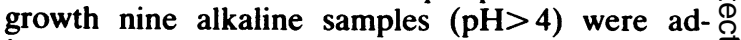
justed to $\mathrm{pH} 1.8$ before culture. Similarly, 47 acidic $\stackrel{\mathbb{Q}}{\mathbb{Q}}$ samples $(\mathrm{pH}<4)$ were adjusted to $\mathrm{pH} 7$. Cultures of pH manipulated samples showed that after acidification the microflora were changed or absent in the 
Table 3 Laboratory findings in 45 RA patients with or without atlantoaxial subluxation (AAS) and treatment with or without second line or third line drugs, or both ( $>$ two months)

\begin{tabular}{|c|c|c|c|c|c|}
\hline & \multicolumn{2}{|c|}{ First line drugs only } & \multicolumn{3}{|c|}{ Second line or third line drugs, or both } \\
\hline & $\begin{array}{l}\text { Females } \\
(n=8)\end{array}$ & $\begin{array}{l}\text { Males } \\
(n=5)\end{array}$ & $\begin{array}{l}\text { Females with } \\
\text { ASS }(n=8)\end{array}$ & $\begin{array}{l}\text { Females without } \\
\text { ASS }(n=8)\end{array}$ & $\begin{array}{l}\text { Males } \\
(n=16)^{*}\end{array}$ \\
\hline Mean age, years (range) & $53(38-62)$ & $55(49-59)$ & $56(24-77)$ & $60(47-73)$ & $57(34-79)$ \\
\hline Mean disease duration, (range) & $5(0.5-18)$ & $2(0.5-6)$ & $9(2-21)$ & $9(0 \cdot 25-24)$ & $8(0 \cdot 25-23)$ \\
\hline Basal achlorhydria $^{\dagger}$ & $2 / 8$ & $2 / 5$ & $7 / 8$ & $2 / 8$ & $4 / 16$ \\
\hline $\mathrm{BAO}, \mathrm{mmol} / 30 \mathrm{~min}(\operatorname{mean} \pm \mathrm{SD})$ & $0.62 \pm 0.59$ & $0.42 \pm 0.52$ & $0.04 \pm 0 \cdot 12^{\ddagger}$ & $0 \cdot 25 \pm 0 \cdot 31$ & $0.65 \pm 0.79$ \\
\hline PAO $<1.3 \mathrm{mmo} / 30 \mathrm{~min}^{+}$ & $2 / 8$ & $1 / 5$ & & & $2 / 16$ \\
\hline $\mathrm{PAO}, \mathrm{mmo} / 30 \mathrm{~min}(\mathrm{mean} \pm \mathrm{SD})$ & $9 \cdot 0 \pm 5 \cdot 9$ & $10 \cdot 0 \pm 9 \cdot 0$ & $1 \cdot 3 \pm 2 \cdot 0^{5}$ & $6 \cdot 4 \pm 4 \cdot 9$ & $9 \cdot 0 \pm 2 \cdot 3$ \\
\hline Plasma gastrin $>100 \mathrm{pg} / \mathrm{ml}^{+}$ & $0 / 7$ & $1 / 3$ & $4 / 7^{11}$ & $3 / 8$ & $1 / 12$ \\
\hline \multirow{2}{*}{$\begin{array}{l}\text { Parietal cell antibody } \\
\text { Positive bacterial cultures in } \\
\text { stimulated period }^{\dagger}\end{array}$} & 0/8 & $1 / 5$ & $5 / 8$ & $2 / 8$ & $1 / 16$ \\
\hline & 0/8 & $0 / 5$ & $5 / 6^{5}$ & $1 / 6$ & $2 / 14$ \\
\hline
\end{tabular}

*Three patients with AAS.

${ }^{\dagger}$ Number of patients.

${ }^{\ddagger} \mathrm{p}<0.02,{ }^{5} \mathrm{p}<0.01 v$ all other female patients.

"The antrectomised patient excluded.

majority of those tested (Table 5). Similar results were obtained by alkalisation of samples before culture. In the samples of changed microflora after $\mathrm{pH}$ adjustment Lactobacillus species (Lactobacillus acidophilus or Lactobacillus plantarum) dominated.

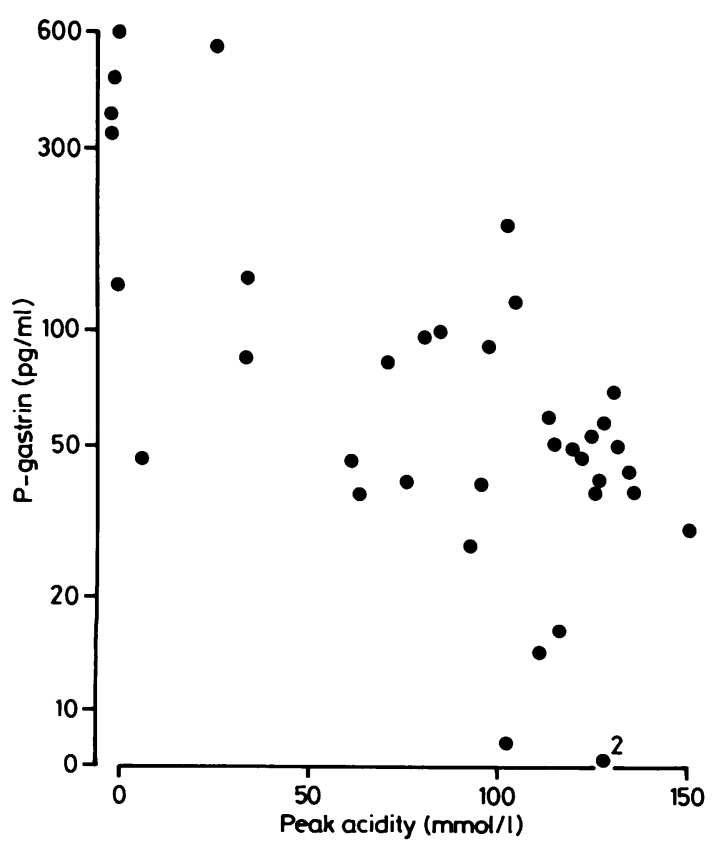

Fig. 2 The acidity of the peak secretion plotted against the logarithm of the plasma gastrin level $(r=-0.69, n=37$, $p<0.001)$.

\section{Discussion}

This study first confirms an association between the gastric secretory state and plasma gastrin levels and second demonstrates growth of micro-organisms in the gastric lumen in female patients with severe rheumatoid arthritis.

More than one third of the patients had basal achlorhydria and almost one fourth were achlorhydric or had very low acid response after stimulation. This is in agreement with earlier studies. ${ }^{1236}$ Short et al found that gastric achlorhydria was significantly more frequent in RA patients below 40 years of age, in particular among female patients. ${ }^{2}$ Thus RA in females is apparently associated with the development of achlorhydria early in life. In addition, the secretory state of the patients showed positive correlation with the duration of the disease, whereas correlation with age was absent.

As observed previously ${ }^{468}$ a large number of RA patients had raised plasma gastrin values. The gastrin levels correlated inversely with the acid secretory status, an observation which is in agreement with the study by De Witte et al. ${ }^{6}$ In a few patients in this series a high plasma gastrin coexisted with normal gastric acidity. This combination has been reported previously by Rooney $e t$ al both in RA patients ${ }^{7}$ and in experimental arthritis in the rat. ${ }^{10}$ In the experimental series there seemed to be correlation between plasma gastrin and severity of inflammation, but any causative relation remains to be proved. Other peptides, such as substance $P,{ }^{23}$ may also vary with the degree of inflammation. The gastrin- and insulin-like immunoreactivities in joint 
480 Henriksson, Uvnäs-Moberg, Nord, Johansson, Gullberg

Table 4 Concentrations of gastrin and insulin in plasma and joint fluid taken simultaneously in fasting subjects (patients Nos 1-9) and at variable times after food intake (patients Nos 10-12)

\begin{tabular}{|c|c|c|c|c|c|c|c|}
\hline \multirow[t]{2}{*}{ Patient No } & \multicolumn{2}{|c|}{ Gastrin $(p g / m l)$} & \multirow[t]{2}{*}{$\begin{array}{l}\text { Gastrin ratio } \\
\text { joint/plasma }\end{array}$} & \multicolumn{2}{|c|}{ Insulin $(\mu \mathrm{U} / \mathrm{ml})$} & \multirow{2}{*}{$\begin{array}{l}\text { Insulin ratio } \\
\text { joint/plasma }\end{array}$} & \\
\hline & Plasma & Joint & & Plasma & Joint & & \\
\hline 1 & 600 & 210 & 0.35 & 11 & 6 & 0.55 & Fasting \\
\hline 2 & 430 & $26(1)$ & $0 \cdot 60$ & 14 & 9 & $0 \cdot 64$ & Fasting \\
\hline 3 & 364 & 314 & 0.86 & 12 & 5 & 0.42 & Fasting \\
\hline 4 & 106 & 44 & 0.42 & 18 & 15 & 0.83 & Fasting \\
\hline 5 & 95 & 75 & 0.79 & 19 & 30 & 1.58 & Fasting \\
\hline 6 & 88 & 48 & 0.55 & 12 & 9 & 0.75 & Fasting \\
\hline 7 & 39 & 38 & 0.97 & 38 & 18 & 0.47 & Fasting \\
\hline 8 & 38 & 23 & $0 \cdot 60$ & 18 & 9 & 0.50 & Fasting \\
\hline 9 & 41 & 18 & 0.44 & 25 & 16 & $0 \cdot 64$ & Fasting \\
\hline 10 & 48 & 86 & 1.79 & 53 & 20 & $0 \cdot 38$ & Postprandial $(1-2 h)$ \\
\hline 11 & 5 & 44 & $8 \cdot 8$ & 17 & 5 & 0.29 & Postprandial $(1-2 \mathrm{~h})$ \\
\hline 12 & 147 & 86 & 0.59 & 160 & 17 & $0 \cdot 11$ & Postprandial ( $1 \mathrm{~h})$ \\
\hline
\end{tabular}

fluid from the patients appear to reflect the plasma levels. It is thus likely that the peptides reach the joints from circulating blood.

Raised gastrin levels together with PCA in achlorhydric patients are suggestive of a type $A$ gastritis. ${ }^{24}$ This type is associated with various organ specific autoimmune diseases. Atrophic changes of the gastric mucosa have been reported previously in patients with $\mathrm{RA}^{25} 26$ and are common in Sjögren'ssyndrome. ${ }^{27}$ The same combination of increased $\subseteq$ plasma gastrin and PCA is seen in pernicious $\overrightarrow{\widehat{D}}$ anaemia. ${ }^{24}$ It is noteworthy that not a single patient $\vec{\odot}$ in the present study had manifest PA or reducedo plasma levels of vitamin $B_{12}$, which is in accordance with earlier studies. ${ }^{27} 28$

A majority of patients with basal achlorhydria or

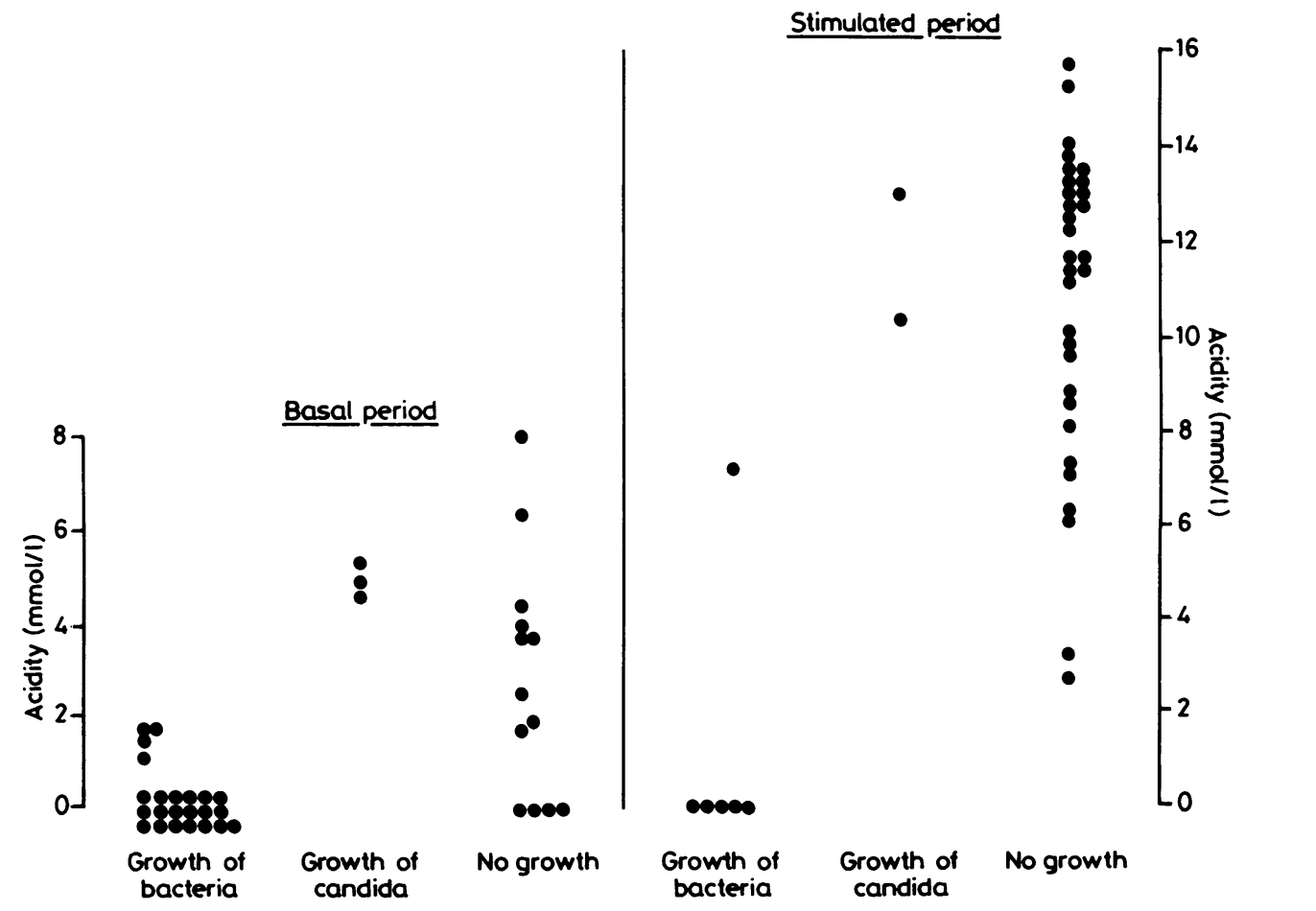

Fig. 3 The relation between gastric acidity (mmolll) and occurrence of micro-organisms in gastric secretion during basal and stimulated periods. 


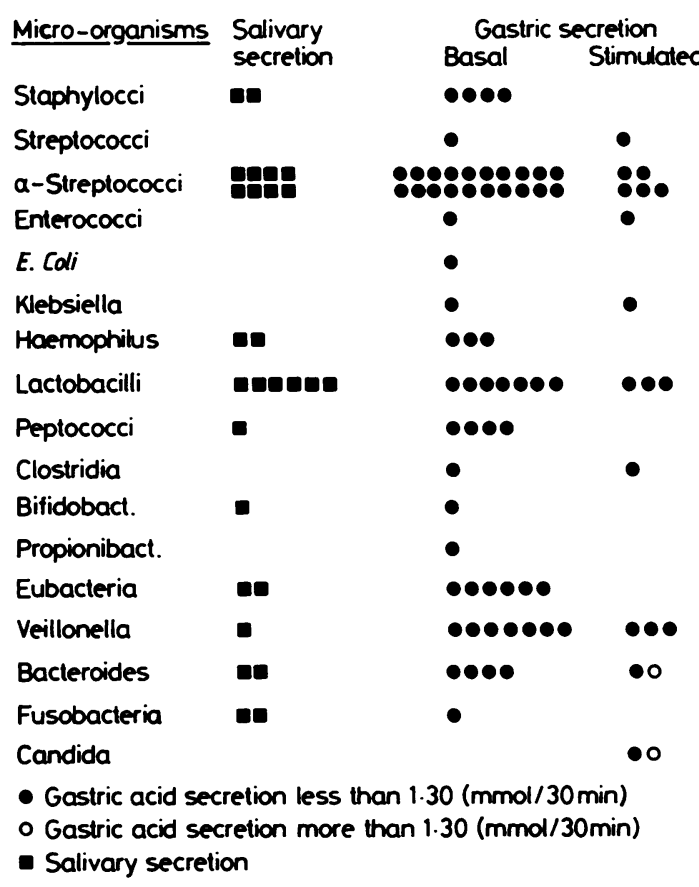

Fig. 4 The different micro-organisms cultivated from saliva and gastric secretion (basal and stimulated) and their relation to acid secretion.
Gastric function in $R A$

very low gastric acidity had micro-organisms in the stomach, as evaluated by positive cultures of basal gastric secretion, whereas none of the patients with acid secretion in the basal period had a positive bacterial culture. This is in agreement with earlier studies of gastric microflora. ${ }^{12} 13$ Similar microflora were found in saliva and gastric secretion, and a faecal type of flora was found only in an antrectomised patient.

Interestingly, the gastric contents became sterile when patients responded to pentagastrin with acid secretion. The slightest in vivo acidification of the

Table 5 Effect of $p H$ adjustments on the microflora in 56 gastric samples. Alkaline samples $(\mathrm{pH}>4)$ were adjusted to $\mathrm{pH} 1.8$ and acid samples $(\mathrm{pH}<4)$ were adjusted to $\mathrm{pH} 7$ before culture

\begin{tabular}{|c|c|c|c|c|}
\hline \multirow[t]{3}{*}{ Original sample } & \multicolumn{4}{|c|}{ After $p H$ adjustment } \\
\hline & \multicolumn{2}{|c|}{ Acidification $(n=9)$} & \multicolumn{2}{|c|}{ Alkalisation $(n=47)$} \\
\hline & $\begin{array}{l}\text { Changed } \\
\text { flora }\end{array}$ & Negative & $\begin{array}{l}\text { Changed } \\
\text { flora }\end{array}$ & Negative \\
\hline Positive & 4 & 5 & 5 & 7 \\
\hline Negative & 0 & 0 & 4 & 31 \\
\hline
\end{tabular}

Patients No 12 $\begin{array}{llll}3 & 4 & 5 & 6\end{array}$

$\begin{array}{llllllll}7 & 8 & 9 & 10 & 11 & 12 & 13 & 14\end{array}$

Micro-organisms

Staphylococci

Streptococci

a-Streptococci

Enterococci

E. Coli

Klebsiella

Haemophilus

Lactobacilli

Peptococci

Clostridia

Bifidobact.

Propionibact.

Eubacteria

Veillonella

Bacteroides

Fusobacteria

Candida

No growth
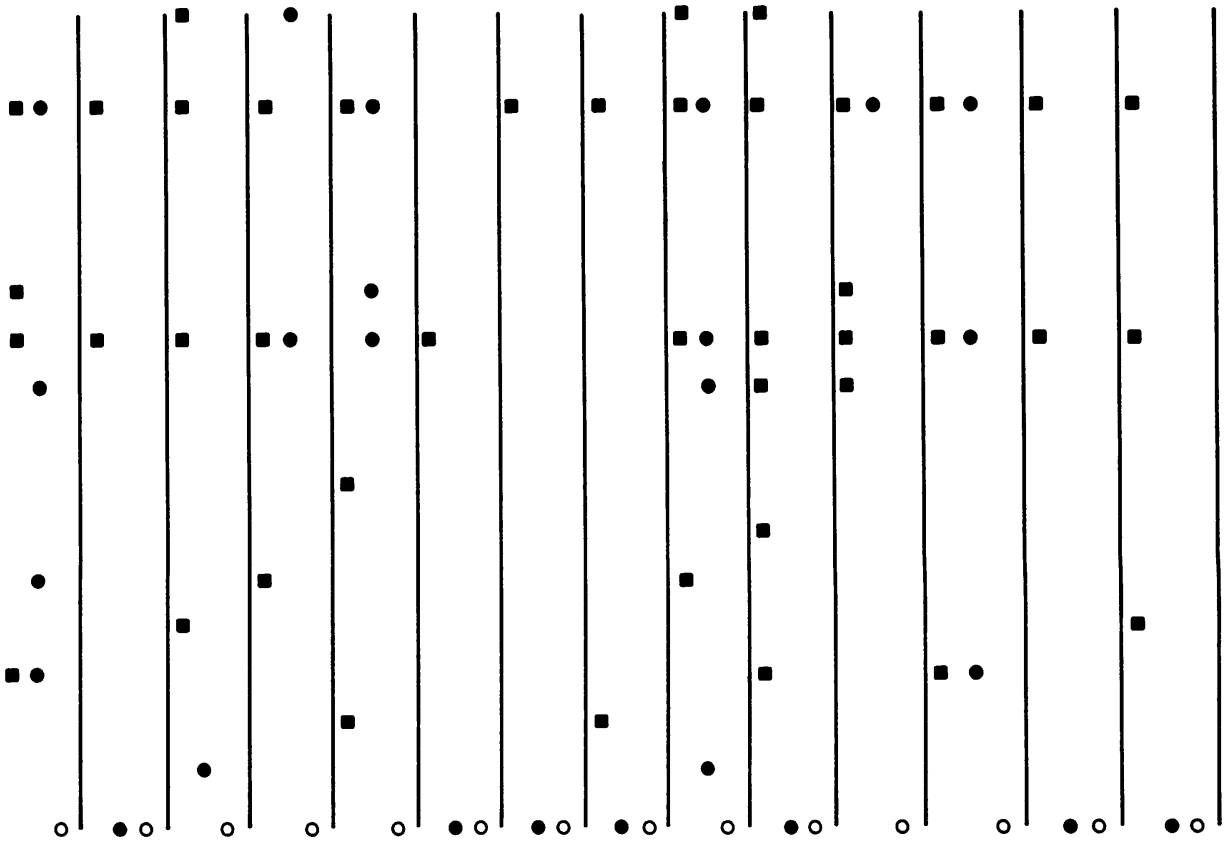

- Salivary secretion - Basal secretion ostimulated secretion

Fig. 5 The relation between the micro-organisms in salivary and gastric secretion (basal and stimulated) in each patient. 
stomach was effective in eliminating microbial growth as opposed to in vitro $\mathrm{pH}$ manipulation. Microbial overgrowth of the non-acid stomach may thus be cleared away even by minute amounts of secreted acid. The possibility of the concomitant release of other antimicrobial agents should also be considered.

In a comparative study of various rheumatic disorders Rooney et al found hypergastrinaemia only in patients with rheumatoid arthritis. ${ }^{29}$ Edström reported in 1939 that gastric achlorhydria in RA patients was associated with high disease activity and disturbed peripheral circulation with neuropathic disturbances.' This investigation reported that the secretory anomaly of the stomach disappeared in a number of RA patients, who experienced parallel improvements in general clinical condition, joint swelling, and peripheral circulation. It was concluded that the depressed secretion must be a phenomenon secondary to the rheumatic tissue process.

In this study the gastric acid secretion rates showed no clear correlation with the clinical disease activity, but the PAO tended to be lower in patients with high inflammatory activity. A subgroup of female patients who had been treated with second line or third line drugs, or both, and with atlantoaxial subluxation had lower basal and stimulated acid secretion rates, higher frequency of PCA, and positive bacterial cultures compared with females without this complication. Such subluxation is more common in females ${ }^{311}$ and indicates a destructive form of RA. ${ }^{31}$ The gastric mucosa changes and atlantoaxial subluxation in the female patients studied may both be consequences of a severe rheumatic disease, but the possibility should also be considered that disturbances in the gastrointestinal flora may influence the course of the disease. The role of antirheumatic medication in the pathogenesis of gastric changes in RA is unclear.

Biologically active substances derived from gastrointestinal contents or from imbalance in peptide hormone systems, or both, may be of significance in the pathogenesis of RA. As there seem to be an association between destructive RA and low gastric acid secretion it seems important to study further the mechanisms and the consequences of these disturbances in the gastric secretory functions.

These investigations were supported by grants from the Swedish Society against Rheumatism. the King Gustaff $V 80$ year Foundation, and the Swedish Medical Research Council.

\section{References}

1 Edström G. Magensekretion und Grundumsatz bei den chronischen rheumatischen Arthritiden. Acta Med Scand 1939; 99: 228-56.
2 Short C L. Bauer W. Reynolds W E. Gastric acidity. In: S Rheumatoid arthritis. Cambridge. Massachusetts: Harvard $\equiv$ University Press. 1957: 361-6.

3 Olhagen B. Intestinal Clostridium perfringens in arthritis and allied conditions. In: Dumonde D C. ed. Infection and immunologv in rheumatic diseases. Oxford: Blackwell. 1976: 141

4 Rooney P J. Vince J. Kennedy A C. et al. Hypergastrinaemia in rheumatoid arthritis: disease or iatrogenesis? Br Med J 1973: ii: 752-3.

5 Rowden D R. Taylor I L. Richter J A. Pinals R S. Levine R A. Is hypergastrinaemia associated with rheumatoid arthritis? Gut 1978: 19: $1064-7$.

6 De Witte T J. Geerdink P J. Lamers C B. Boerbooms A M. Van der Korst J K. Hypochlorhydria and hypergastrinaemia in rheumatoid arthritis. Ann Rheum Dis 1979: 38: 14-7.

7 Rooney P J. Kennedy A C. Gray G H. Sturrock R D. Buchanan K D. Dick W C. Serum immunoreactive gastrin in rheumatoid arthritis. Ann Rheum Dis 1976: 35: 246-50.

8 Altomonte L. Sommella L. Negrini A P. Palumbo P. Magarò M. Greco A V. Serum gastrin in rheumatoid arthritis. Mineria Med 1982: 73: 1761-3.

9 Rooney P J. Dick W C. Buchanan K D. Imric R C. An animal model to study the relationship between immunoreactive gastrin and inflammatory arthritis. Nature 1973: 246: 497-8.

10 Rooney P J. Dick W C. Imrie R C. Turner D. Buchanan K D. Ardill $\mathbf{J}$. On the relationship between gastrin. gastric secretion, and adjuvant arthritis in rats. Ann Rheum Dis 1978; 37: 432-5.

11 Uvnäs-Wallensten K. Uvnäs B. Relcase of gastrin on stimulation of the sciatic and brachial nerves of the cat. Acta Phvsiol Scand 1978: 103: 349-51.

12 Gray J D A. Shiner M. Influence of gastric $\mathrm{pH}$ on gastric and jejunal flora. Gut 1967: 8: 574-81.

13 Drasar B S. Shiner M. McLeod G M. Studies on the intestinal flora: 1. The bacterial flora of the gastrointestinal tract in healthy and achlorhydric persons. Gastroenterology 1969: 56: 71-9.

14 Olhagen B. Mansson I. Intestinal Clostridium perfringens in rheumatoid arthritis and other collagen diseases. Acta Med Scand 1968: 184: 395-402.

15 Gullberg R. Possible role of alterations of the intestinal flora in rheumatoid arthritis. Rheumatol Rehabil 1978: suppl: 5-10.

16 Bennett J C. The infectious etiology of rheumatoid arthritis. Arthritis Rheum 1978: 21: 531-8.

17 Ropes M W. Bennett G A. Cobbs S. Jacox R. Jessar R A. Revision of diagnostic criteria for rheumatoid arthritis. Bull Rheum Dis 1958: 9: 175-6.

18 Steinbrocker O. Traeger C H, Batterman R C. Therapeutic O criteria in rheumatoid arthritis. JAMA 1949: 140: 6.59-62.

19 Nilsson $G$. Increased plasma gastrin levels in connection with $\frac{D}{O}$ inhibition of gastric acid responses to sham feeding following bulbar perfusion with acid in dogs. Scand J Gastroenterol 1975: No
10: $273-7$.

20 Nilsson G, Uvnäs-Wallensten K. Effect of teasing, sham $N$ feeding and feeding on plasma insulin concentrations in dogs. N In: Radioimmunoassay: methodology and applications in $\omega$ physiology and in clinical studies. Stuttgart: Thieme. 1974; 91-7. (Commemorative Issue for Salomon A Berson.)

21 Holdeman L V, Cato E. Moore W E C. In: Anaerobe $\frac{\mathrm{C}}{(\mathrm{D}}$ laboratory manual. 4th ed. Blacksburg, Virginia: Virginia Polytechnic Institute and State University, 1977.

22 Heimdahl A. Nord C E. Effect of phenoxymethylpenicillin and clindamycin on the oral. throat and faecal microflora of man. Scand J Infect Dis 1979; 11: 233-42.

23 Levine J D. Clark R. Devor M. Helms C. Moskowitz M A. (D) Basbaum A I. Intraneuronal substance P contributes to the $\sigma$ severity of experimental arthritis. Science 1984: 226: 547-9.

24 Strickland R G. Mackay. I R. A reappraisal of the nature and 
significance of chronic atrophic gastritis. Am J Dig Dis 1973; 18: 426-40.

25 Louyot P, Tamisier J N, Jeanpierre J, Pourel J, Zannetti A, Bertrand $P$. Le comportement gastrique au cours des rhumatismes inflammatoires sous incidence médicamenteuse. $R e v$ Rhum Mal Osteoartic 1974; 41: 725-32.

26 Marcolongo R, Bayeli P F, Montagnani M. Gastrointestinal involvement in rheumatoid arthritis: a biopsy study. $J$ Rheumatol 1979; 6: 163-73.

27 Maury C P J, Törnroth T, Teppo A-M. Atrophic gastritis in Sjögren's syndrome: morphologic, biochemical and immunologic findings. Arthritis Rheum 1985; 28: 388-94.
28 Pitcher C S, Lindsay D J, Hill A G S. Absorption of vitamin $B_{12}$ in rheumatoid arthritis. Ann Rheum Dis 1970; 29: 533-6.

29 Rooney P J, Grennan D M, Sturrock R D, Brooks P M, Dick W C. Serum immunoreactive gastrin: specificity for rheumatoid arthritis, bimodality of distribution, and failure of effect of antiinflammatory drugs. Ann Rheum Dis 1976; 35: 40-5.

30 Winfield J, Cooke D, Brook A S, Corbett M. A prospective study of the radiological changes in the cervical spine in early rheumatoid disease. Ann Rheum Dis 1981; 40: 109-14.

31 Bland J H. Rheumatoid arthritis of the cervical spine. $J$ Rheumatol 1974; 1: 319-42. 